\title{
DOCENTES ATUANTES EM UM CURSO DE FORMAÇÃO
}

Simone Gonçalves Franzati ${ }^{1}$

RESUMO O presente artigo tem por objetivo investigar os docentes atuantes em um curso de formação de professores, abordando a relação educador e aprendiz, o educador reflexivo e suas competências, processo de ensino e aprendizagem, em sala de aula, sendo que é um espaço onde se desenvolve um processo de interações e influências. Através de uma pesquisa bibliográfica e documental, saliento que o fracasso escolar no ensino básico em nosso país, atualmente, dentre alguns fatores é fruto de uma má formação no ensino superior. A análise apontou que o maior desafio de um docente atuante em um curso de formação de professores é lidar com a diversidade que ocorre dentro de sala de aula.

ABSTRACT This article aims to investigate the teachers working in a training course for teachers, addressing the relationship between educator and leaner, the educator and their reflective skills, teaching and learning in the classroom, and is space where develops a process of interactions and influences. Through a literature search and document, I note that educational failure in elementary school in our country today, among some of the factors is the result of poor training in higher education. The analysis pointed out that the biggest challenge a teacher active in a training course for teachers is to deal with the diversity that occurs within the classroom.

Palavras Chaves: Educador reflexivo e suas competências, formação de professores em ensino superior, processo de ensino - aprendizagem.

Key-words: Educator and reflexive skills, training of teachers in higher education, teaching - learning.

\footnotetext{
1 Graduada em Pedagogia - Faculdades Integradas Campos Salles. Pós - graduada (Latu-Sensu): Formação Docente para o Ensino Superior - Universidade Nove de Julho. Mestranda: Educação, Arte e História da Cultura - Universidade Presbiteriana Mackenzie. Email: simonefranzati@ hotmail.com
} 


\section{Introdução}

Pesquisar é desenvolver um olhar, é assumir uma postura, um olhar que não é o da ação" (CHARLOT,in: PIMENTA, 2002:103).

No decorrer de minha vida acadêmica (graduação e pós - graduação), encontrei alguns educadores, os quais conduziram não satisfatoriamente suas turmas de maneira que o ensino do aprendiz fosse significativo, tornando - os cidadãos críticos. Percebo que muitos educadores possuem um conhecimento profundo de suas disciplinas, mas muitos não conseguem criar possibilidades de ensino - aprendizagem, toda essa problemática resulta se na falta em didática, competência e em lidar com a diversidade em sala de aula, como bem lembra Bordenave (1988:16):

Talvez devido a esta falta de preparação didática, muitos professores demonstram insegurança em seu relacionamento com os alunos e para manter sua auto-imagem, recorrem a atitudes protetoras, tais como emprego de ironia e sarcasmo para dominar os rebeldes, e outras.

A instituição de ensino superior segundo o autor não promove o adequado funcionamento dos mecanismos de comunicação, coordenação e integração entre educadores e como conseqüência, impera o individualismo, não tem um "espirit de corps" no corpo docente, há falta de complementaridade entre disciplinas, coordenação inadequada de horários e de classes, introdução a inovação é uma grande dificuldade e faltam assistência e orientação psicológica e vocacional para os aprendizes.

Ao começar a preparar meu artigo científico em uma disciplina específica, citei as frases acima, ressaltando toda essa problemática que ocorre no ensino e, quando o educador ${ }^{2}$ entregou o trabalho corrigido, colocou ao lado dessas frases: (Analise de senso comum $^{3}$ ).

2 Está experiência que ocorreu em minha vida acadêmica, e que gostaria de trazer aos leitores desse artigo, ocorreu em uma disciplina de um módulo específico para elaborar o artigo científico, quero deixar claro que o orientador no qual me auxiliou excelentemente nesse artigo não tem nenhuma relação a isso!

3 Entendemos senso comum, como um conhecimento evidente, prático e pragmático que faz coincidir causa e intenção, é uma leitura do real que se reproduz pela trajetória de vida de um determinado grupo social. Agora o senso comum, na atuação do educador, constitui a matéria prisma basilar do conhecimento pedagógico, sendo um saber geral e prático, por todos os educadores que já foram um dia aprendizes ( SANTOS, 1989: 32 - 40). 
Felizmente tenho o respaldo de autores consagrados que são pesquisadores nessa área como Bornenave (1988); Masetto (2003); Masetto (1994); Masetto (1992); Masetto; Abreu (1995); Gusdorf (1995) e Moysés (1995), que ressaltam muito bem tudo o que está sendo mencionado.

Segundo Behrens (in Masetto, 1998: 62), a queixa mais recente dos gestores universitários recai sobre denúncias, veremos algumas delas: $\mathrm{O}$ educador sabe muito conteúdo, mas não sabe ensinar; o educador é um profissional competente, mas dá aulas para si próprio; o educador reclama que ganha pouco e, por isso, não se dedica a profissão como deveria; falta negligência por parte do educador e comenta que tem coisas mais importantes para fazer; entre outras. Agora, o mesmo autor (in Masetto, 1998: 66 - 67), sugere alguns pressupostos que poderá reverter esse quadro: O professor precisa ser crítico, reflexivo, pesquisador, criativo e saber praticar efetivamente as teorias no qual propõe a seus alunos; Por outro lado o aluno precisa ser curioso, criativo e reflexivo, buscar inovações, questionar suas ações, ser critico e criar um hábito de leitura e, que seja capaz de analisá - la, criticá - la, refletir sobre ela; A opção metodológica, precisa vir assentada em pressupostos progressista aliada ao ensino com pesquisa, que complete uma visão holística ${ }^{4}$, alicerçada numa tecnologia inovadora.

Sendo assim, este presente artigo tem por objetivo tratar a relação educador aprendiz, abordando: a formação do educador reflexivo, o processo de ensino e aprendizagem e o ensino, através de uma pesquisa bibliográfica e documental, salientando que o fracasso escolar no ensino básico atualmente é fruto de uma má formação no ensino superior. O maior desafio de um docente atuante em um curso de formação de professores é lidar com a diversidade que ocorre dentro de sala de aula.

Masetto; Abreu (1990) ressalta que existe uma lacuna no desempenho do educador universitário; esse educador caracteriza - se como um especialista em sua área de conhecimentos, este é o critério para a sua seleção e contratação, porem, esse profissional não necessariamente domina a área educacional e pedagógica, agora há uma enorme disposição do educador a supera - la. Essa lacuna também ocorre em crianças e adolescentes ao longo de sua

4 Para entendermos a visão holística da educação é necessário sabermos a sua origem. A palavra Holismo - vem do grego holon - significa inteiro, integral, totalidade, realidade, que faz referência a um universo feito de conjuntos integrados que não pode ser reduzida a simples soma de sua parte.

"O termo educação holística foi proposto pelo americano Miller (1997) para designar o trabalho de um conjunto heterogêneo de liberais, de humanistas e de românticos que têm em comum a conviç̧ão de que a personalidade global de cada criança deve ser considerada na educação. São consideradas todas as facetas da experiência humana, não só o intelecto racional e as responsabilidades de vocação e cidadania, mas também os aspectos físicos, emocionais, sociais, estéticos, criativos, intuitivos e espirituais inatos da natureza do ser humano". (Yus, 2002: 16). 
vida estudantil; acumulam lacunas de conhecimentos e competências, assim, quando se propõem outro olhar para o fenômeno da aprendizagem, quando se apontam os prejuízos causados por propósitos educacionais incompatíveis com as necessidades modernas, quando teorias pedagógicas reforçam as consequências nefastas de praticas autoritárias de ensino, quando se propõe para o professor reciclar suas práticas político - pedagógicas, quando é imperativo inserir os projetos sociais no projeto pedagógico das escolas, é importante lembrar que os educadores que estão hoje na escola pública passaram por esse mesmo processo de escolarização que se repete ao longo da história, como bem lembra o Vitor Paro (2001).

Rizzo (2004) concorda com Paro (2001), dizendo que os educadores são resistentes a mudanças, reproduz em sala de aula os mesmos métodos e paradigmas no quais foram submetidos em sua longa jornada acadêmica, sendo um circulo vicioso em nosso sistema educacional.

É importante salientar que atualmente as tecnologias de informação chegaram para ficar e para ajudar os educadores em seus métodos de ensino, mas para isso ocorrer de maneira satisfatória, Masetto (2004: 199), propõe aos educadores refletirem e buscarem constantemente reciclar sobre essas alterações em nossa sociedade, oriundas da tecnologia para o trabalho acadêmico na universidade, exigir mudanças profundas, mas para isso é preciso, estar aberto às mudanças que estão ocorrendo em nosso entorno, diálogo, intercomunicação, parceria com as mais diversas fontes de produção de conhecimento, revisão e reformulação de bancos de dados e informações e a implantação de novos processos informativos e de comunicação.

Para que possamos ver mudanças significativas no ensino básico em nosso país, precisamos mudar a paisagem cultural nos cursos de graduação que formam esses profissionais de educação, por isso, começarei o primeiro capitulo retratando o fracasso escolar.

No segundo capítulo veremos autores consagrados que ressalta uma preocupação central no ensino, salientando o processo de aprendizagem de seu aprendiz, o professor reflexivo e que esse profissional de educação tenha jogo de cintura para lidar com as adversidades que ocorrem dentro de sala de aula e, no ultimo capítulo veremos quais são as competências que esse educador necessita para sua prática docente.

Espero que esse artigo apresente algumas inquietações e que de alguma forma sirva para os profissionais de educação rever a sua prática docente, meu intuito não é criticar o ensino, mas através de autores / pesquisadores, é trazer algumas possibilidades de melhorias, principalmente sabendo que é possível. Quero discutir, analisar, trocar idéias, experiências, 
sucessos e fracassos de maneira científica a nossa atual realidade educacional. Por isto, este artigo não terá um fecho, continuará aberto para analises, criticas e sugestões. Ficarei muito feliz em recebê-las, por intermédio de email ou de outros meios, darmos continuidade a esse diálogo.

\section{Fracasso escolar}

Para Patto (1987), o fracasso da escola publica é o resultado inevitável de um sistema gerador de obstáculos ${ }^{5}$ à realização de seus objetivos ressaltando a precariedade das condições de trabalho do professor, insatisfação profissional, lacunas de formação, a pequena duração da jornada escolar e do ano letivo, a gratuidade apenas nominal da escola pública.

Além dessa problemática analisada por Patto (1987), Vitor Paro (2001), complementa dizendo que existem fatores determinantes a resistência nas mudanças do processo de ensinoaprendizagem. Entre eles o fator determinante socioculturais, dizem a respeito aos valores, crenças, hábitos e concepções dos educadores envolvidos no processo; os condicionantes psicobiográficos referem-se à configuração de personalidade dos educadores envolvidos e principalmente às marcas deixadas nessa personalidade pelas experiências vividas.

Agora Charlot (2002), discorda de que os fatores determinantes do processo de ensino aprendizagem seja o educador como lembra Paro (2001); ressalta que a questão central de tudo é a pratica do aluno, e não a pratica do professor, não importa se o professor é da pedagogia nova ou da pedagogia antiga; o que importa é a pratica do aluno, se o aluno não fizer o trabalho intelectual, não vai aprender e, sucessivamente irá fracassar e, juntamente com ele o professor, portanto, o trabalho do professor não é ensinar, é fazer o aluno aprender. A definição do professor é permitir ao aluno aprender. O que realmente importa é se o professor ajuda o aluno a desenvolver uma atividade intelectual. O professor só pode desempenhar essa função, se ele também tem uma atividade intelectual: "Não sabemos o que é exatamente o professor, ou que é exatamente o oficio do professor" (CHARLOT, in: PIMENTA, 2002: 89).

Para Carlini e Scarpato (2004), o processo de ensino e aprendizagem gera um vínculo entre quem ensina e quem aprende, nessa relação de ensino e aprendizagem, há dinâmica,

5 Patto (1987) relata uma crise na escola pública brasileira que acaba sendo fruto do descaso de nossos governantes e em função dessa política com discursos vazios, a escola passou a ter profissionais mal preparados, desmotivados e para complicar descompromissados com sua docência e com a educação, o próprio educador extravasa todos esses fatores mencionados acima em seus aprendizes, resultando em fracasso escolar. 
interação, diálogo que se propicia a troca de conhecimentos nos âmbitos cognitivo, afetivo e motor entre os participantes do processo.

Agora Charlot (2002) acredita que o fracasso escolar ocorre porque os alunos têm dificuldades em aprender o que foi proposto pelo educador: "o fracasso escolar não existe, e sim, existem alunos que encontram dificuldades para aprender" (p. 94), o fracasso escolar acabou tornando-se um vírus, uma doença que está ameaçando as crianças, o autor prefere ressaltar "em dificuldades escolares" em vês "de fracasso escolar e de coisas gerais demais.

Comecei a dizer em meu artigo através de autores como Charlot (2002), Vitor Paro (2001), Patto (1987), que a escola pública em nosso país é resultante em fracasso escolar, professores desmotivados, governantes omissos, falta material didático - pedagógico, pouco tempo para realizar suas atividades envolvendo o ensino e aprendizagem porque o próprio educador tem que trabalhar em mais que um emprego para sustentar sua família, lacunas em sua formação, no qual é imprescindível e, todos esses fatores entre tantos outros acaba comprometendo a qualidade de ensino em escolas publicas. Um dos objetivos de meu artigo científico é um fator resultante em fracasso escolar mencionado acima, sendo as lacunas na formação desse docente, depois que esse aprendiz perpassou em um curso de formação de professores e esse profissional começa a atuar em seu campo profissional ele fracassa, juntamente com seu aluno.

\section{O educador}

[...] aprender a ser professor é um processo que começa com a própria escolarização básica, continua nos cursos de formação inicial e se perpetua durante o exercício profissional. Ou seja, tornar-se professor é um processo de formação contínuo que, tendo um começo, dificilmente terá um fim. (TANCREDI, 1998:359).

A epígrafe acima menciona que o ofício de ser educador é um trabalho árduo e de formação contínua, mas muitos desses profissionais de educação, segundo Rizzo (2004), são resistentes a mudanças: se no Brasil a metade da população foi alfabetizada por um método, eles tendem a alfabetizar pelos mesmos mecanismos, entre outras causas, o ensino universitário é 
deficiente $^{6}$; as escolas tanto públicas quanto as privadas, de todos os níveis, reproduzem os modelos.

\begin{abstract}
Nós professores, vimos ao longo do tempo, baseando nossas ações em crenças rígidas, criadas ao longo da história e mantidas por nossa insegurança de mudar. Estamos diante da era da incerteza, com a função de preparar alunos para as mudanças, e nos mantermos ainda arraigados à existência de verdades absolutas de posturas inflexíveis e fundamentos em um modelo comportamental de aprendizagem. Sabemos que o melhor caminho para a mudança de hábitos é a mudança de crenças e mudar de crenças é um processo doloroso, que, às vezes, parece nos tirar do chão. Precisamos construir um novo chão, que esteja dentro de nós, para que possamos pisá-lo por inteiro. (LAGO, 2004: 161).
\end{abstract}

Rizzo (2004), e Lago (2004), concordam entre si, dizendo que os educadores são resistentes as mudanças e que é imprescindível criar novos hábitos, crenças, uma nova cultura para que possamos mudar a real conjuntura da educação brasileira.

Muitos educadores demonstram insegurança em seu relacionamento com os aprendizes e, automaticamente para manter certa autoridade / auto - imagem recorre a atitudes protetoras, comunicações formais, um exagerado nível de exigência nas avaliações e o mais significativo é o emprego de ironia e sarcasmo, agora outros assumem atitudes de humildade e subordinação, reduzem a carga de trabalho, tolera a indisciplina, fazem vista grossa a ausência injustificada e, sobretudo facilitam nas avaliações (BORDENAVE, 1988:16) e, além disso, Fernendes; Ferla (in Masetto, 1998), conclui que os educadores têm uma insatisfação com a profissão docente às causas são: salários baixos, falta de didática e uma grande perda de seu status profissional em nossa sociedade.

Há inúmeros fatores geradores de resistência ${ }^{7}$, por parte dos educadores à obrigatoriedade de cuidar do aspecto pedagógico na formação de professores, sendo eles: Os que já são professores pensam que não tem mais nada aprender em sua área de atuação, muito embora, esses profissionais não tenham qualquer fundamentação teórica para tal exercício; Aqueles que saibam que o título de mestre lhes confira o "direito" de virem a ser, algum dia docente, a princípio mesmo não querendo exercer essa profissão; Muitos docentes de diversos

6 Muitos professores universitários dificilmente passaram pela experiência de ser um professor alfabetizador e não sabem responder as questões práticas, nunca alfabetizaram crianças com as mais variadas necessidades especiais

7 Muitos profissionais resistem a "aprender", em suas concepções pessoais, pensam que já sabem ensinar. (VASCONCELOS, in MASETTO, 1998: 85). 
cursos, que cursaram um modelo de pós - graduação não entende a justificativa para as mudanças e nem vêem necessárias para a sua vida acadêmica (VASCONCELOS, in MASETTO, 1998: $90-91)$.

A exigência é que o professor assuma uma postura reflexiva sobre sua prática:

A reflexão oferece a eles (os professores) a oportunidade de se tornarem conscientes das crenças e suposições subjacentes a tal (sua) prática, assim como de examinarem a validade de suas práticas na obtenção de metas estabelecidas. Pela reflexão, o seu desenvolvimento profissional. Pela reflexão, passam a ter condições de tornar explícitas suas teorias implícitas, também denominadas de teorias práticas, de teorias pessoais, e que têm força na configuração de práticas pedagógicas (MIZUKAMI, 2000: 142).

Behrens (in Masetto, 1998: 64), alerta pra a necessidade de formação contínua fundamentada na reflexão sobre e na ação do educador, esse processo reflexivo aponta caminhos para deixarmos de "fazer pelo fazer" e atribuir na vida docente "saber por que fazer", sendo proposto por Schön em Nóvoa (1992: 26):

\footnotetext{
Conhecimento na ação, reflexão na ação e reflexão sobre a ação e sobre a reflexão na ação ganha uma pertinência acrescida no quadro do desenvolvimento pessoal dos professores nos remete par a consolidação do terreno profissional de espaços de (auto) formação participada. Os momentos de balanço retrospectivo sobre os percursos pessoais e profissionais são momentos em que cada um produz a, "sua" vida, o que, no caso dos professores, é também produzir a sua profissão.
}

Além de uma postura reflexiva segundo Mizukami (2000), e a reflexão sobre e na ação proposto Schön em Nóvoa (1992), Masetto (1998), propõem aos educadores empenho em possibilitar aprendizagem de valores políticos e sociais, para que os aprendizes valorizem o conhecimento, atualização contínua, a cooperação, solidariedade, criticidade e o último não menos importante são o trabalho em equipe.

\section{Competência do educador universitário}

Só recentemente os professores universitários começaram a se conscientizar de que seu papel docente do ensino superior, como no exercício de qualquer profissão, exige capacitação própria e específica que não se restringe a ter um diploma... Exige isso tudo, e competência pedagógica, pois ele é um educador. (MASETTO, 2003:13). 
Moysés (1995) quer deixar claro que ao fazermos uso da palavra competência ou a expressão "educador competente", não lhe atribuímos uma conotação com o enfoque tecnicista, é obvio que o educador por si só é capaz de transformar a realidade de seu entorno, e sem dúvida, o fator predominante quando se pensa em melhoria de ensino é a competência do educador. Enfoca que um dos problemas da competência pedagógica tem uma raiz profunda na questão política da educação. Competente segundo a autora é aquele educador que tudo se faz para que seu aprendiz se torne um cidadão critico e muito bem informado, com plenas condições de compreender o mundo e atuar no mesmo, não aceitando tudo o que lhe é imposto.

As gerações futuras não serão diferentes da presente, com todos os seus defeitos e prejuízos de ordem moral, se não tratarmos da educação da infância e da juventude; dessa juventude que será a sociedade do amanhã. (MARIO, 1999: 25 ).

As gerações futuras mencionada na epígrafe acima nos remetem a um mundo melhor na dependência do trabalho da educação em nossa sociedade, dos educadores empenhados no processo de aprendizagem e competentes.

Masetto (1998; 2003), procura discutir quais seriam as competências para os educadores universitários:

1. O docente seja competente em uma determinada área de conhecimento ${ }^{8}$. Sendo no mínimo requisitos básicos para a docência em uma área específica, a exigência e de que seus conhecimentos sejam sempre atualizados, através de congressos, simpósios, entre outros: "O conhecimento de si mesmo é portanto a chave do melhoramento individual "(MARIO, 1999:20).

2. O docente precisa ter um domínio da área pedagógica, esse requisito é muito carente em nossos educadores, pode ser porque não tiveram oportunidades nessa área, ou vêem como supérfluo em sua carreira docente;

O processo de ensino e aprendizagem, porque o objetivo maior de um educador é a aprendizagem dos educandos como já havia mencionado é importante que nossos aprendizes aprendam conhecimentos, informações, desenvolva intelectualmente e que desenvolva suas habilidades humanas, como, valores e que sejam comprometidos com os problemas existentes em nossa sociedade.

8 "Entendendo - se que o conhecimento é uma busca permanente, admitimos que ele seja prático, pois se dá graças a experiência prática do sujeito que nela se relaciona com o objeto. Por outro lado, admitimos que o conhecimento é social: a inter - relação com a dialética sujeito - objeto só é possível, no que se refere à construção do conhecimento, na complexa e variada trama das relações dos homens com os outros homens. Por fim, entendemos que o conhecimento é histórico, construído pelos homens através dos tempos, em uma luta incessante pela apreensão do objeto, em um "longo e difícil caminho da ignorância ao conhecimento", em um processo que, como a própria prática social, vai do pensamento complexo ao pensamento mais complexo" (ALVES; GARCIA, in ALVES, 1993: 75). 
O docente como conceptor e gestor de currículo. Atualmente é muito frequente o educador lecionar em duas ou mais matérias, sem fazer relações explícitas com as demais disciplinas do mesmo curso, as causas, evidenciam, porque o educador pensa que seus aprendizes sabem que essa matéria é importante para a sua profissão, ou o educador desconhece as relações entre a sua matéria e o restante do currículo, uma vez que não participou da elaboração do mesmo, e, foi contratado para lecionar apenas uma disciplina, por isso, é importante ao educador perceba que o currículo abrange o desenvolvimento da área cognitiva ${ }^{9} \mathrm{e}$ abrangendo também a aprendizagem de habilidades ${ }^{10}$. O currículo está preocupado com os aspectos éticos da profissão, valores sociais, culturais, políticos, econômicos, a participação e evolução na sociedade.

Fávero (in ALVES, 1993: 69 - 70) discute algumas informações sobre o currículo ${ }^{11}$ :

Os professores não sabe nem se o currículo novo já esta funcionando; $40 \%$ nunca viram o currículo e não sabem, inclusive, como a sua disciplina se articula com a mesma disciplina no semestre seguinte, e seguramente, a maioria dos professores não conhece o currículo.

Procura - se envolver o professor no currículo. É muito difícil. "Vive o seu mundo a sua disciplina, sem interesses por nada" (...) "e não vê o ensino como um todo, nas suas correlações com outras disciplinas.

A rotina do ensino de graduação é entrar em sair da sala de aula, e cada professor só pensa na sua disciplina; na maioria das vezes não participa de discussões, constituindo - se em uma ilha de universidade.

A relação educador - aprendiz e aprendiz - aprendiz no processo de ensino aprendizagem, Masetto $(1998 ; 2003)$ ressalta é que precisamos de educador orientador / parceiro e co - responsável das atividades, corrigindo -os quando necessário, incentive a aprendizagem, planeje seu curso juntos, criando possibilidades contínuas de feedback, que permite ao aprendiz aprender.

9 Área cognitiva em relação à: aquisição, elaboração, produção de conhecimento, acesso ao conhecimento existente, reprodução do próprio conhecimento, reconstrução do próprio conhecimento, identificação de diferentes pontos de vista sobre o mesmo assunto, imaginação, criatividade, solução de problemas (MASETTO, 1998:21).

10 Aprendizagem de habilidades, como por exemplo: trabalhar em equipe e em equipe multidisciplinar, comunicar-se com os demais aprendizes e com pessoas de fora de seu ambiente universitário, fazer relatórios, pesquisar em bibliotecas, hemerotecas, videotecas, usar o computador para atividades acadêmicas e profissionais, entre outras (MASETTO, 1998:21).

11 Depoimentos de metade dos coordenadores da Comissão de Carreira da UFRGS, onde predominam o desconhecimento dos educadores sobre o currículo. 
O domínio da tecnologia educacional é um fator imprescindível, segundo Masetto (2003; 1998:22), houve tempos que se pensou que o computador resolveria todos os problemas da educação e outros educadores negaram - se a tecnologia, dizendo que bastasse dominar o conhecimento e transmiti - los aos seus aprendizes, atualmente:

[...] encontramo - nos em uma situação que defende a necessidade de sermos eficiente e eficaz no processo de aprendizagem: queremos que nossos objetivos sejam atingidos de forma mais completa e adequada possível e, para isso, não podemos abrir mão da ajuda de uma tecnologia pertinente.

3. O exercício da dimensão política (didática) é imprescindível ao educador. $\mathrm{O}$ educador jamais deixa de ser um cidadão, inserido em uma sociedade, que faz parte de um processo dialético e histórico, esse educador tem uma visão de mundo, de homem, de sociedade, de cultura e de educação, alguém que é comprometido com a sociedade, sua comunidade e como profissional de educação jamais poderia deixar esses fatores de lado. A reflexão crítica e adaptação são fundamentais para o educador compreender como vive - se e pratica - se a cidadania e inserindo esses contextos em sala de aula como: selecionando leituras de textos pertinentes, referindo - se em aula diversos temas e permitindo ao aprendiz adquirir conhecimento, debatendo e manifestando suas opiniões e respeito aos outros aprendizes que por ventura vierem divergir de suas opiniões: "Conciliar o técnico com o ético na vida profissional é fundamental para o professor e para o aluno" (MASETTO, 1998: 24).

\footnotetext{
Nossos alunos precisam discutir conosco, seus professores, os aspectos políticos de sua profissão e de seu exercício nesta sociedade, para nela saberem se posicionar como cidadãos profissionai.s (MASETTO, 1998:25).
}

Mario (1999: 54), juntamente com Masetto (1998), preocupa - se com o futuro de nossos aprendizes, se não nos preocuparmos com o hoje, com a educação, como educadores empenhados em mudar a paisagem cultural, hábitos e valores, será difícil notar mudanças em nossa sociedade:

Há um elemento que não se ponderou bastante, e sem o qual a ciência não passa de teoria: a educação. [...] Quando se pensa na massa de indivíduos diariamente lançados na corrente da população, sem freios, entregues ao próprios instintos, deve - se admirar das consequiências desastrosas deste fato? Quando esta arte for conhecida, compreendida e praticada, o homem seguira no mundo os hábitos de ordem e previdência para si mesmo e para os seus, de respeito pelo que é respeitável, hábitos que lhe permitirão atravessar de maneira menos penosa os maus dias inevitáveis. A desordem e a imprevidência são duas chagas que somente uma educação bem 
compreendida pode curar. Nisso esta o ponto de partida, o elemento real do bem estar, a garantia da segurança de todos.

Por tudo o que foi relatado nesse capítulo, penso que é pertinente ao educador, que no qual se propõe a mudar seus pensamentos e ações: "Mude, mas mude devagar, porque a direção é mais importante do que a velocidade " ( CLARICE LISPECTOR, in: LAGO, 2004 : 53 ).

O educador precisa ter em mente que a história da construção de suas competências pode ter início, mas nunca um fim, como foi mencionado na primeira citação desse capítulo, porque somos seres inacabados:

\begin{abstract}
[...] seres que estão sendo, seres inacabados, inconclusos em e com uma realidade que, sendo histórica também, é igualmente inacabada. Na verdade, diferentemente dos outros animais, que são apenas inacabados, mas não são históricos, os homens se sabem inacabados. Têm a consciência de sua inconclusão. (FREIRE, 2002: 72-73).
\end{abstract}

Por isso enquanto educador penso que: "Seja a mudança que você deseja ver no mundo" ( GANDHI, in: LAGO, $2004: 15$ ).

\title{
Metodologia
}

Este presente artigo científico é uma pesquisa bibliográfica, segundo Gil (2002: 45), a "principal vantagem da pesquisa bibliográfica reside no fato de permitir ao investigador a cobertura de soma de fenômenos muito mais ampla do que aquela que poderia pesquisar diretamente". A pesquisa bibliográfica também pode ser considerada como aquela que permite uma maior redução de custos, devido os dados pesquisados estarem disponíveis para futuras pesquisas, também possibilita a coleta de dados históricos só possíveis através da pesquisa bibliográfica.

O desenvolvimento a reflexão de novos conceitos e procedimentos de pesquisa científica estão sempre acompanhados de uma reflexão epistemológica, capazes de sustentar profundas mudanças de produzir conhecimento científico, nos quais permitam aos pesquisadores terem acesso ao significado na produção teórica sobre o assunto a ser estudado (REY, 2011). 
Gil (2002), alerta para a desvantagem da pesquisa bibliográfica quando esta pode levar ao erro, se for realizada através de fontes secundárias que apresentam dados equivocados. Para corrigir esta possível falha, este projeto visa coletar dados de publicações certificas de autores e entidades reconhecidas no meio cientifico.

\section{Análise}

Comecei meu artigo científico ressaltando que para vermos mudanças significativas no ensino básico em nosso país, precisamos mudar a paisagem cultural nos cursos de graduação que formam esses profissionais de educação. O malogro da escola que, durante anos, traduziu-se pela dificuldade de acesso a escola, pelos índices de analfabetismo e por estatísticas alarmantes de evasão e repetência já nas séries iniciais, configura-se hoje pela comprometida qualidade de ensino, frustrando ainda o anseio dos alunos de efetivamente aprender. $\mathrm{O}$ fracasso escolar persiste e está ligado ao sucesso na aprendizagem; e esse sucesso está ligado diretamente na formação de profissionais que atuam nessa realidade educacional.

Agora, a sala de aula onde se formam profissionais de educação é um espaço de confinamento, por um determinado tempo é um espaço onde se desenvolve interações e influencias tanto na relação educador e aprendiz como aprendiz e aprendiz e está inserida numa instituição, que por sua vez está filiada a um subsistema educacional, sendo parte de um sistema sociopolítico - cultural econômico e religioso brasileiro, estando vinculada a realidade histórica do Ocidente. E cada um desses seguimentos tem seus valores, direção, opção, prioridades, que se disseminam e se impõem através de normas, leis, propagandas entre outras, e percebemos que direta ou indiretamente a relação professor e aluno, suas funções, seus trabalhos, decisões, entre outras, estão profundamente influenciados por esta realidade ( MASETTO; ABREU, 1990: 126).

Sendo assim, o educador tem uma grande influencia diretamente em sala de aula, em suas relações com o aprendiz, no planejamento, nas condições de aprendizagem; seu modo de agir, por sua vez, reflete valores e padrões da sociedade.

Como afirma Masetto (2003:16), os educadores atuantes devem estar preocupados, sobretudo em ensinar seus aprendizes a aprender, ao invés de serem fontes de conhecimentos, e que devem ser tomadas providencias adequadas para pesquisar, atuar e melhorar as habilidades pedagógicas, por intermédio de programas de desenvolvimento pessoal. O autor ressalta 
claramente a importância de um aprimoramento contínuo, voltadas para um objetivo em comum: formar pessoas que sejam profissionais competentes e cidadão co-responsáveis pela melhoria da qualidade de vida em nossa sociedade, sendo assim, o papel do educador como facilitador, não é o de ensinar, mas ajudar o aluno aprender, não é transmitir conhecimentos, mas criar possibilidades para que o aluno adquira essas informações como bem lembra Freire (1993) e Masetto; Abreu (1990).

Vygotsky (1987:92) ressalta o papel do educador mediador na relação sujeito/ objeto: "[...] o professor, trabalhando com o aluno, explicou, deu informações, questionou, corrigiu o aluno e o fez explicar".

A epigrafe acima consiste em ensinar para a compreensão, destacando algumas expressões: trabalhando com o aluno - atitude de integração; ele "explicou" e "deu informações" - buscar uma estrutura cognitiva dos aprendizes, que servirão como ponto de partida para o que se quer ensinar; o professor "questionou e corrigiu o aluno" - o educador procurou verificar se a sua fala havia sido compreendida e porventura corrigiu os erros ${ }^{12}$; “...e o fez explicar" - fazer o aprendiz explicar, sendo assim o educador poder verificar se o que está sendo explicado e de origem real ou uma pseudo - aprendizagem.

Além de o educador precisar ser um facilitador como lembra Masetto; Abreu (1990) e Freire (1993), Vygotsky (1987) como um mediador no processo de ensino e aprendizagem, autores como Mizukami (2000) e Nóvoa (1992), ressaltam que o educador tem que ter uma postura reflexiva e refletir sobre e na ação docente.

Veras; Ferreira (2011) analisa a postura do educador em sala de aula e a experiência de aprendizagem do aluno, sendo assim, o educador exerce um importante papel de mediador, que poderá ou não favorecer a construção do conhecimento pelo aprendiz.

A formação é um processo de construção de identidade profissional, perpassa: pela formação acadêmica, pela história de vida do educador, pode e deve ser aperfeiçoada pela prática; demanda: atualização / formação continuada, relação entre teoria e prática e postura ativa do futuro educador rumo à construção de seu conhecimento científico.

12 O bom educador saberá fazer perguntas que desequilibre a estrutura cognitiva de seus aprendizes, fazendo - o evoluir no sentido de uma nova reestruturação. Como aponta o próprio Vygotsky (1984), a capacidade de abstrair é fundamental no processo de ensino e aprendizagem conceituais, para que isso ocorra de forma satisfatória, o educador precisa inibir as idéias secundárias e particulares, ficando mais fácil ao educador a tarefa de ajudar o aprendiz a inibir certos pensamentos secundários e somente abstraindo os fundamentais, para poder atingir os objetivos pretendidos. 
O educador recebe influências da sociedade, comunidade escolar, própria história de vida do educador dentro de uma instituição de ensino.

O educador precisa estar sempre atento, criticamente aberto ao novo, diferentes ciências, diferentes recursos pedagógicos e diferentes procedimentos didáticos, visando à melhor adequação do exercício de sua profissão. Sobre esse exercício necessita: responsabilidade social, competência técnica, reflexividade, resiliência, estética, ética, prazer, dedicação, inclusão e boa qualidade: recursos financeiros, recursos humanos, recursos físicos - espaciais, recursos didáticos.

Atualmente conversando com alguns educadores atuantes em pós - graduação, a queixa maior deles é que todos são "amiguinhos", mas na hora em que precisa trabalhar em equipe e compartilhar saberes é cada educador por si próprio, e Masetto (1998), cita várias vezes, que os educadores precisam trabalhar em equipe, é imprescindível para o ensino aprendizagem, sendo que o foco central da aprendizagem é o aluno.

Há muito que dizer e pensar sobre o ofício de ensinar e texto algum daria conta dessa complexa reflexão, simplesmente o porquê é uma profissão do humano, se dá na interação entre humanos, num trabalho complexo, condenado a viver entre contradições muitas vezes insuperáveis. O que o educador pode fazer é manter seu estado de lucidez sobre sua trajetória acadêmica e aprender com suas experiências, entender que a autonomia é importante, e, sobretudo, estar certo que essa profissão lhe agrada. Trabalhar com aprendizes é um desafio, agora trabalhar bem, conseguindo bons resultados o desafio é ainda maior. 


\section{Referências Bibliográficas}

ALVES, Nilda (ORG). Formação de professores: pensar e fazer. 2 ed. São Paulo: Cortez, 1993.

BAUER, Martin W. e GASKELL George. Pesquisa qualitativa com texto: imagem e som. 4 ed. Rio de Janeiro: Vozes, 2002.

BORDENAVE, Juan Días; PEREIRA, Adair Martins. Estratégias de ensino - aprendizagem. 10 ed. Petrópolis: Vozes, 1988.

CARLINI, Alda Luiza; SCARPATO, Marta. Os procedimentos de ensino fazem a aula acontecer. São Paulo: Avercamp, 2004.

CHARLOT, Georges. Professores, para que?: para uma pedagogia da pedagogia. São Paulo: Martins Fontes, 2003.

FREIRE, Paulo. Pedagogia da Autonomia: saberes necessários à prática educativa. São Paulo: Paz e Terra, 2003.

GIL, Antonio Carlos. Como Elaborar Projetos de Pesquisa. 4 ed. São Paulo: Atlas, 2002.

LAGO, Samuel. Conversas com quem gosta de ensinar. Campina Grande do Sul: Editora Lago, 2004.

MARIO, M. A. de. Visão espírita da educação. Matão: O clarim, 1999. 
MASETTO, Marcos T. Docência na universidade 3 ed. São Paulo: Papirus 1998. . Aulas Vivas. São Paulo: MG Editores Associados, 1992. Didática: A aula como centro. São Paulo: FTD, 1994. ; ABREU, Maria Célia de. O professor universitário em aula. 8 ed. São Paulo: MG Editores Associados, 1990.

Competência pedagógica do professor universitário.São Paulo:

Summus, 2003.

MIZUKAMI, M. G. N. In ABRAMOWICZ, A. \& Mello, R. R. de (orgs) Educação: Pesquisas e Práticas. Campinas: Papirus, 2000.

MOYSÉS, Lucia. O desafio de saber ensinar. 2 ed. São Paulo, Papirus, 1995.

NÓVOA, António (org.). As Organizações Escolares em Análise. Lisboa: Publicações Dom Quixote, 1992.

PARO, Vitor H. A reprovação escolar: renuncia à educação. São Paulo: Editora Yamá, 2001.

PATTO, Maria H. Souza. A produção do fracasso escolar: história de submissão e rebeldia. São Paulo: [s.n.], 1987.

REY, Fernando Luis G. Pesquisa qualitativa em psicologia: caminhos e desafios. São Paulo: Pioneira Thomson Learning, 2011.

RIZZO, Gilda. Por leitores cidadãos. São Paulo: Editora Segmento. Revista educação. Março, 2004.

SANTOS, B. S. Introdução a uma ciência pós - moderna. Rio de Janeiro: Graal, 1989.

TANCREDI, R. S. M. P. Globalização, Qualidade do Ensino e Formação de Professores. Ciência \& Educação, São Paulo, 1998.

VERAS, R. da S.; FERREIRA, S. P. A. A afetividade na relação professor - aluno e suas implicações na aprendizagem, em contexto universitário. Educar em Revista, Curitiba, Brasil, $\mathrm{n}$. 38, p. 219-235, set./dez. 2010. Editora UFPR 
VYGOTSKY, L.S. Pensamento e linguagem. Trad. M. Resende, Lisboa, Antídoto, 1979. A formação social da mente. Trad. José Cipolla Neto et alii. São Paulo, Livraria Martins Fontes, 1984.

. Pensamento e Linguagem. São Paulo: Martins Fontes, 1987.

YUS, Rafael. Educação Integral: uma educação holística para o século XXI.Trad. Daisy Vaz de Morais. Porto Alegre: Artmed, 2002. 